\title{
Testing cladograms by fossil record: the ghost range test
}

\author{
Alexandr P. Rasnitsyn \\ Paleontological Institute, Russian Academy of Sciences, Profsoyuznaya Street 123, 117647 Moscow, Russia
}

Key words: phylogeny, cladogram, ghost range, fossil record, Vespida, Hymenoptera

\begin{abstract}
A method of the ghost range calculation is proposed to assess the congruence between a cladogram and the fossil record and to compare cladograms on this basis. The method is tested on a set of cladograms developed recently to reveal the phylogeny of the hymenopterous insects (Order Vespida), and the results are discussed.
\end{abstract}

\section{Contents}

Introduction

Material

Methods

Results and discussion

254

Conclusion

257

Acknowledgements

258

References

258

\section{Introduction}

It is an ordinary condition in cladistic research that cladograms developed from different data for the same set of taxa often differ significantly from each other. This is crucial since the cladogram comparison is aimed at selecting the most correct one. There are a number of indices that have been developed to estimate statistical features that reflect deviation of the cladogram from the most parsimonious one (Quicke, 1996: 3.2.5). It is not so evident, however, that the evolutionary process does strictly observe the parsimony principle. That is why it seems reasonable to seek a method of assessment less dependent on particular evolutionary concepts.
The fossil record is a source of the evolutionary information that is not strictly dependent on our evolutionary hypotheses, and so in principle it may be used as an external standard in the comparison of cladograms. Of course, the fossil record is imperfect, but so are all our sources of evidence. This is true for cladistics as well, for the character set is never exhaustive, and transformation series composition and polarity are always hypothetical. That is why both sources of the evolutionary information, the fossil record and the cladograms, possess only degrees of 'perfection", but even so are worthy of comparison in testing phylogenies.

There are methods proposed to assess quality of the fossil record based on how it agrees with the cladogram of respective taxa (reviewed by Benton and Hitchin 1997). Unfortunately, these metrics do not fit the reverse task, that is, to test different cladograms of a particular taxon for their extent of congruence with the fossil record. Toward this end, I am proposing here a similar but slightly different approach. In its present form the method is rather rough, but whenever found appropriate, it may be easily improved for more precise calculation.

\section{Material}

Fossil record of the hymenopterous insects (Order Vespida $=$ Hymenoptera) is selected to test the method for the following reasons. Incomplete like any fossil history, the hymenopteran record is rich enough to represent as many as 51 out of 54 ex- 
tant families (e.g., Fig. 1; superfamily Chalcidoidea is used here as a single taxon because there is no cladogram available for it yet). As many as $\mathbf{3 8}$ of these families are recorded starting from the Mesozoic, a time wherein many high-level phylogenetic events occurred, and 20 more families are known to be extinct (mostly since the Mesozoic). A wealth of cladograms have been proposed recently for the family level phylogeny of the order, and this variety allows us to select enough of them to test. The examples are displayed in Figs. 1-6.

Fig. 1 is based on Rasnitsyn (1988), with several minor additions and modifications explained in the caption. Fig. 2 shows the results of the recent parsimony re-consideration of the concept by Rasnitsyn (1988) performed by Ronquist, Rasnitsyn, Roy, Eriksson and Lindgren (1999). Figs. 3-5 are re-drawn from the cladograms in Vilhelmsen (1997: fig. 2), Whitfield (1992: fig. 5), and Brothers and Carpenter (1993: fig. 11), respectively. Fig. 6 represents the apocritan molecular phylogeny performed by Dowton, Austin, Dillon and Bartowsky (1997: fig. 2), with the symphytan families, Orussidae and Stephanidae added after the work of Dowton and Austin (1994). All dendrograms are unified in their style, with the known duration of taxa being indicated by thick lines, relationships by horizontal thin lines, and the implied ghost ranges (see below) by vertical thin lines; the vertical thin line connecting two horizontal ones means noth- ing more than a connection of two parts of a horizontal line.

\section{Methods}

When we convert a cladogram into a phylogenetic tree, we fit the internode length to the paleontologically confirmed minimum duration of a particular subclade. In some cases we have to infer that a clade appears earlier than the fossil record would suggest (vertical thin lines in Figs. 1-6). These inferred cryptic intervals of existence were termed 'ghost ranges' (Norell, 1992). When more than one cladogram is developed for a particular set of taxa, they usually differ in their configuration as well as in the extension of ghost ranges displayed by the respective trees. It is apparent that the smaller these extensions, the better the cladogram fits the fossil record, i. e., the more parsimonious it is in that respect due to a lower degree of inference for the duration of taxa. This is a reason to try and use the ghost range concept for comparison and evaluation of competing cladograms.

Thus we might suggest calculating the ghost ranges in million years, either as their total duration as expressed on the cladogram, or their average duration per node per terminal branch. However, the absolute duration of the geochronological units is still an extensively debatable issue, full

Fig. 1. Relation and duration of the hymenopteran families (superfamily for Chalcidoídea) (modified from Rasnitsyn, 1988). Thíck lines show known longevity, horizontal thin lines - relationshìp, vertical thìn lines - ghost ranges, double thin lines - long ghost ranges (more than two geochronological epochs before entering fossil record). Periods: $\mathrm{T}-$ Triassic $, \mathrm{J}-\mathrm{Jurassic}, \mathrm{K}-\mathrm{Cretaceous,} \mathrm{P}$ - Paleogene, $\mathbf{N}-$ Neogene, $\mathbf{R}$ - contemporary (Holocene). Epochs are shown by subscript indices: ${ }_{1}-$ Lower, $_{2}-$ Middle, $_{3}-$ Upper (in the Cenozoic, $P_{1}-$ Paleocene, $P_{2}-$ Eocene, $P_{3}$ - Oligocene, $N_{1}$ - Miocene, $N_{2}-$ Pliocene). Known ranges are modified for some taxa comparing Rasnitsyn (1988) basing on following sources. Argidae and Sapygidae are found in the Upper Eocene Baltic amber (old data by Brischke 1886, ignored by Rasnitsyn 1988), Megalodontesidae in the Lower Cretaceous of China (Ren et al, 1995; my identification of Jibaissodes Ren, Guo et Ji as a genus of Megalodontesidae), Evaniidae in the Burmese amber of disputably Upper Cretaceous amber (Bashibuyuk et al, 2000), Monomachidae in the Lower Cretaceous of Koonwarra, Australia (Jell and Duncan 1986: fig. 66 F; my identification), Scelionidae and Chalcidoídea (new family) in the lowermost Cretaceous of Mongolia (my identification), Platygastridae in the Upper Cretaceous amber of New Jersey (identified by L. Masner, personal communication by D.A. Grimaldi), Mymarommatidae in the Lower Cretaceous (Aptian) amber of Alava, Spain (my identification), Diapriidae and Bethylonymidae in the Lower Cretaceous of England (Rasnitsyn et al., 1998), Sclerogibbidae in the Miocene Dominican amber (my identification), Embolemidae in the Lower Cretaceous of Transbaicalia and Mongolia (Rasnitsyn 1996b), Scolebythidae in the Upper Eocene Baltic amber (Brothers and Janzen, 1999), Plumariidae in the Upper Cretaceous New Jersey amber (my identification), Rhopalosomatidae and Tiphiidae in the Lower Cretaceous of Brazil (Darling and Sharkey 1990), Sierolomorphidae in the Upper Cretaceous amber of New Jersey and Falsiformicidae in the Lower Cretaceous Lebanese amber (my identification), Formicidae in the Lower Cretaceous of East Siberia (Dlussky 1999). Superfamilies are outlined by boundary lines, except that sometimes members of one and the same superfamily (Karatavitidae and Ephialtitidae, Serphitidae and the rest of Platygastroìdea, Diaprîidae and other Proctotrupoidea) appear separated in the cladogram to simplify it visually. These "orphan" familiěs are marked by a broken arrow. 


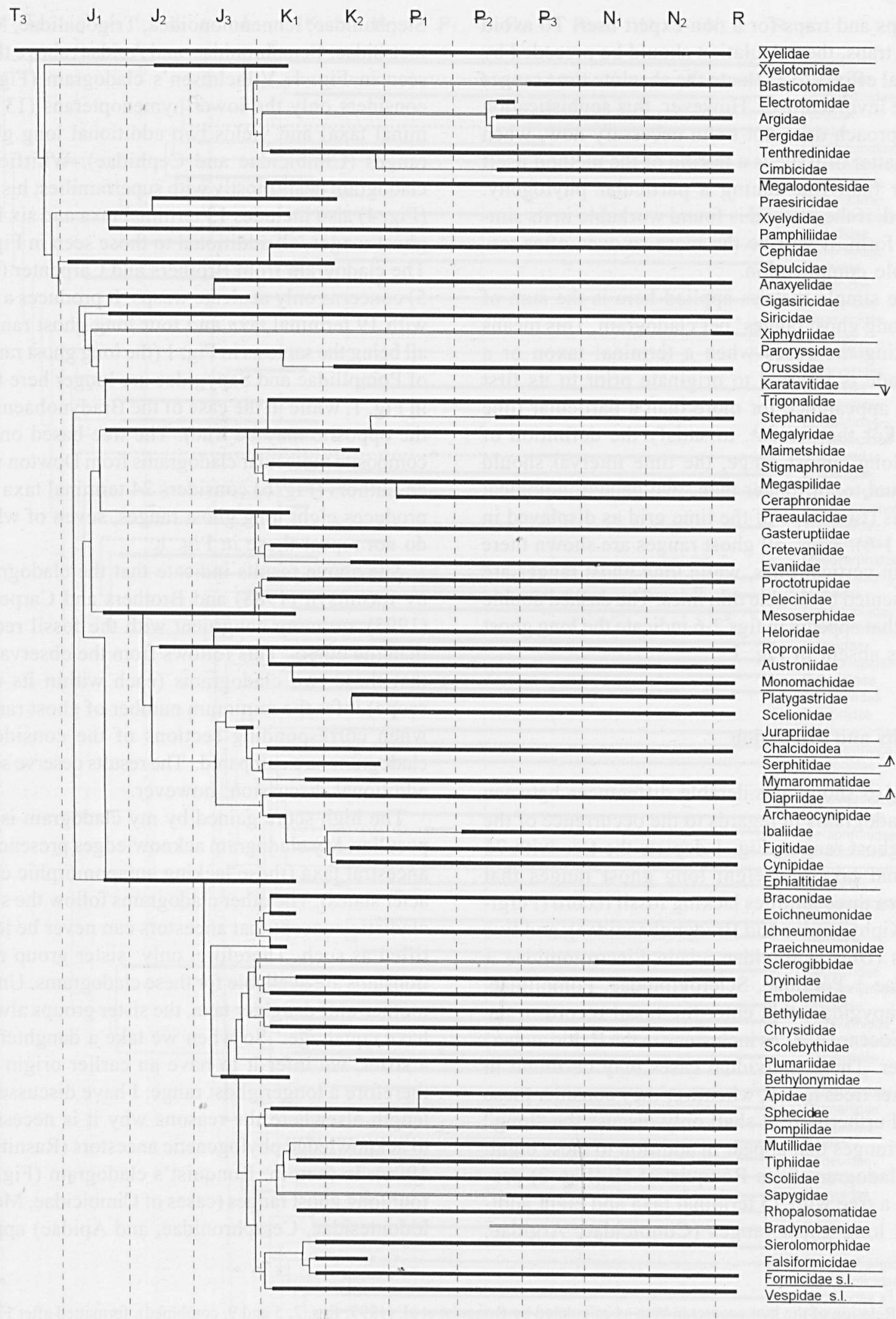


of gaps and traps for a non-expert user. To avoid these traps, the calculation should be preceded by special efforts to evaluate the absolute time ranges of the involved taxa. However, this sophistication of approach does not seem necessary now, when the matter of issue is a testing of the method itself rather than fine tuning a particular phylogeny. Indeed, if the method is found workable in its simplest form, it will be the more so even after reasonable complication.

The simple metrics applied here is the sum of the "long ghost ranges' per cladogram. This means counting the cases when a terminal taxon or a subclade is inferred to originate prior to its first fossil appearance for more than a particular time unit. For the present, to satisfy the definition of the "long" ghost range, the time interval should be equal to, or longer than, two geochronological epochs (two steps of the time grid as displayed in Figs. 1-6). Thus, all ghost ranges are shown there by thin vertical lines, while long ghost ranges are represented by double thin lines. The dashed double lines that appears in figs 2-6 indicate the long ghost ranges absent in Fig. 1.

\section{Results and discussion}

Figs. 1-6 show considerable differences between the cladograms in regards to the occurrence of the long ghost ranges. Fig. 1 depicts the tree with 76 terminal taxa and eight long ghost ranges that concern three families lacking fossil record (Pergidae, Xiphydriidae and Bradynobaenidae), and five others (Blasticotomidae, clade Electrotomidae + Argidae + Pergidae, Sclerogibbidae, Pompilidae, and Sapygidae) that enter the fossil record in the Late Eocene (e. g., as inclusions in the Baltic amber) or later. These individual cases may be found in all other trees tested, whenever they consider these taxa. Furthermore, I shall only discuss the "long" ghost ranges that appear in addition to these eight. The cladogram from Ronquist et al. (Fig. 2) produces a tree with 75 terminal taxa and eight additional long ghost ranges (Cimbicidae, Argidae,
Stephanidae, Ichneumonoidea, Trigonalidae, Maimetshidae, Ceraphronidae, and Apidae) above those seen in Fig. 1. Vilhelmsen's cladogram (Fig. 3) considers only the lower hymenopterans (13 terminal taxa) and yields two additional long ghost ranges (Cimbicidae and Cephidae). Whitfield's cladogram deals mostly with superfamilies; his tree (Fig. 4) also includes 13 terminal taxa and six long ghost ranges, all additional to those seen in Fig. 1. The cladogram from Brothers and Carpenter (Fig. 5) concerns only aculeate wasps. It produces a tree with 19 terminal taxa and four long ghost ranges, all being the same as in Fig. 1 (the long ghost ranges of Pompilidae and Sapygidae are longer here than in Fig. 1, while in the case of the Bradynobaenidae the opposite may be true). The tree based on the composite molecular cladograms from Dowton with co-authors (Fig. 6) considers 24 terminal taxa and produces eight long ghost ranges, seven of which do not repeat those in Fig. 1.

The above results indicate that the cladograms by Rasnitsyn (1988) and Brothers and Carpenter (1993) are more congruent with the fossil record than the others. This follows from the observation that these two cladograms (each within its own scope) infer the minimum number of ghost ranges when corresponding sections of the considered cladograms are compared. The results deserve some additional discussion, however.

The high score gained by my cladogram is not peculiar. My cladogram acknowledges presence of ancestral taxa (those lacking autapomorphic character states). The other cladograms follow the strict cladistic concept that ancestors can never be identified as such. Therefore, only sister group relationships are available for these cladograms. Unlike mother-and-daughter taxa, the sister groups always have equal age. So when we take a daughter for a sister, we infer it to have an earlier origin and therefore a longer ghost range. I have discussed at length elsewhere the reasons why it is necessary to acknowledge phylogenetic ancestors (Rasnitsyn, 1996). In fact, in Ronquist's cladogram (Fig. 2), four long ghost ranges (cases of Cimbicidae, Megalodontesidae, Ceraphronidae, and Apidae) appear

Fig. 2. Relation of the hymenopteran taxa as calculated by Ronquist et al. (1999: figs. 2, 5 and 9, combined), formatted after Fig. 1. Dashed double line - long ghost ranges additional to those seen in Fig. 1. 


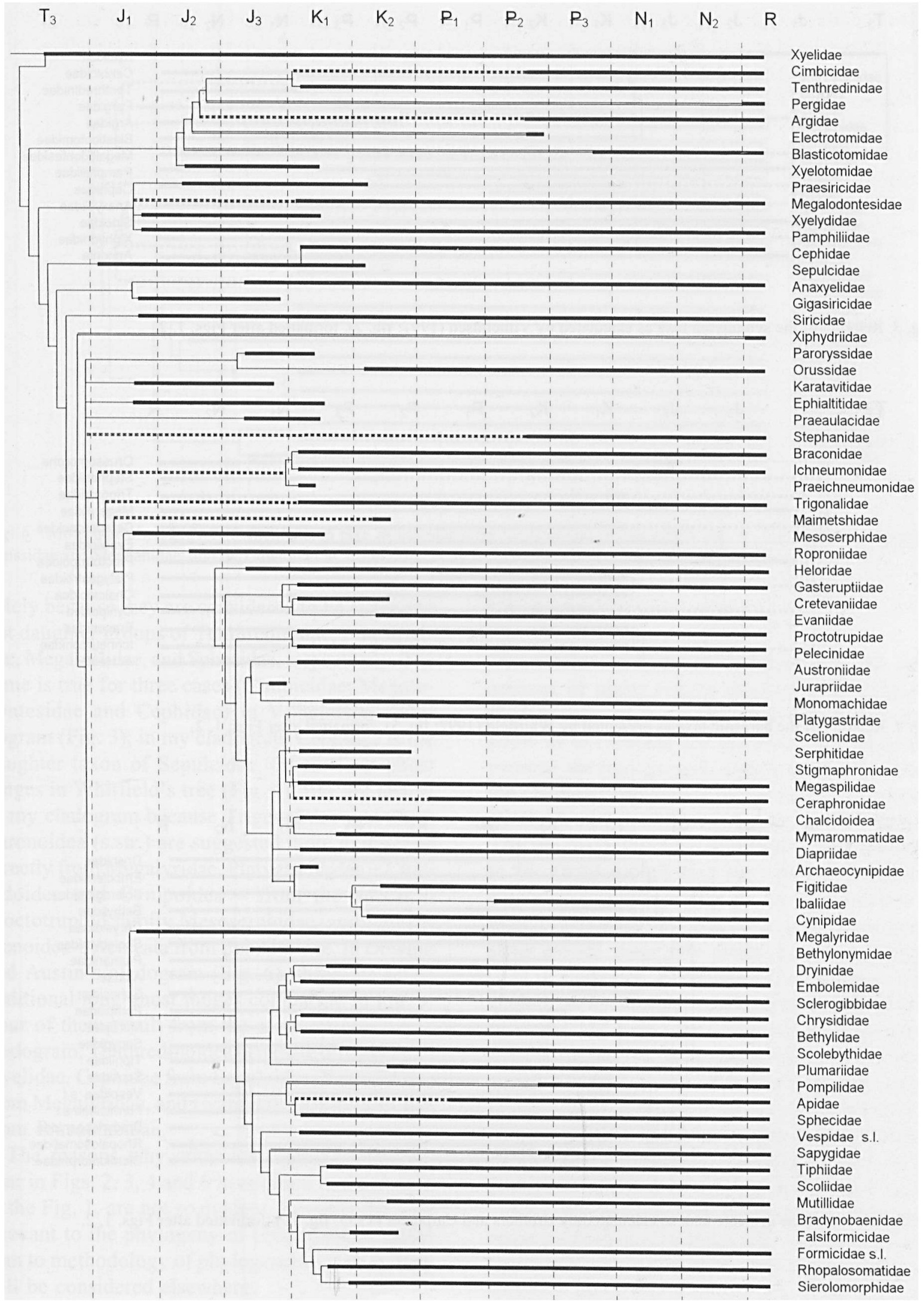




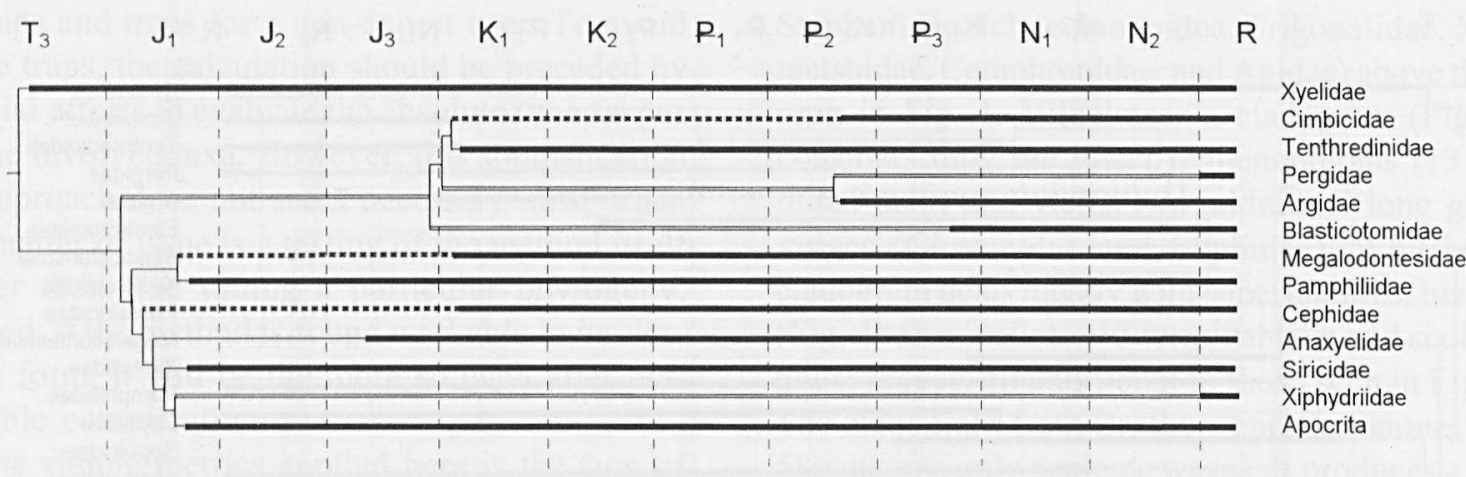

Fig. 3. Relation of the symphytan taxa as calculated by Vilhelmsen (1997: fig. 2), formatted after Figs. 1, 2.

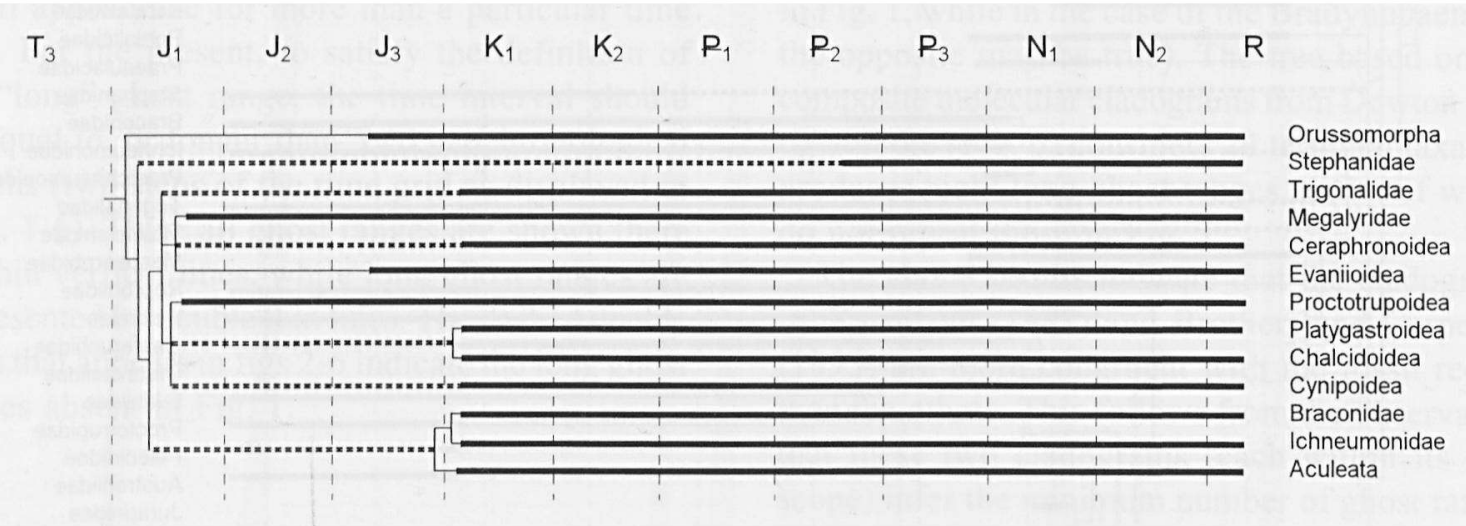

Fig. 4. Relation of the parasitic taxa as presented by Whitfield (1992: fig. 5), formatted after Figs. 1, 2.

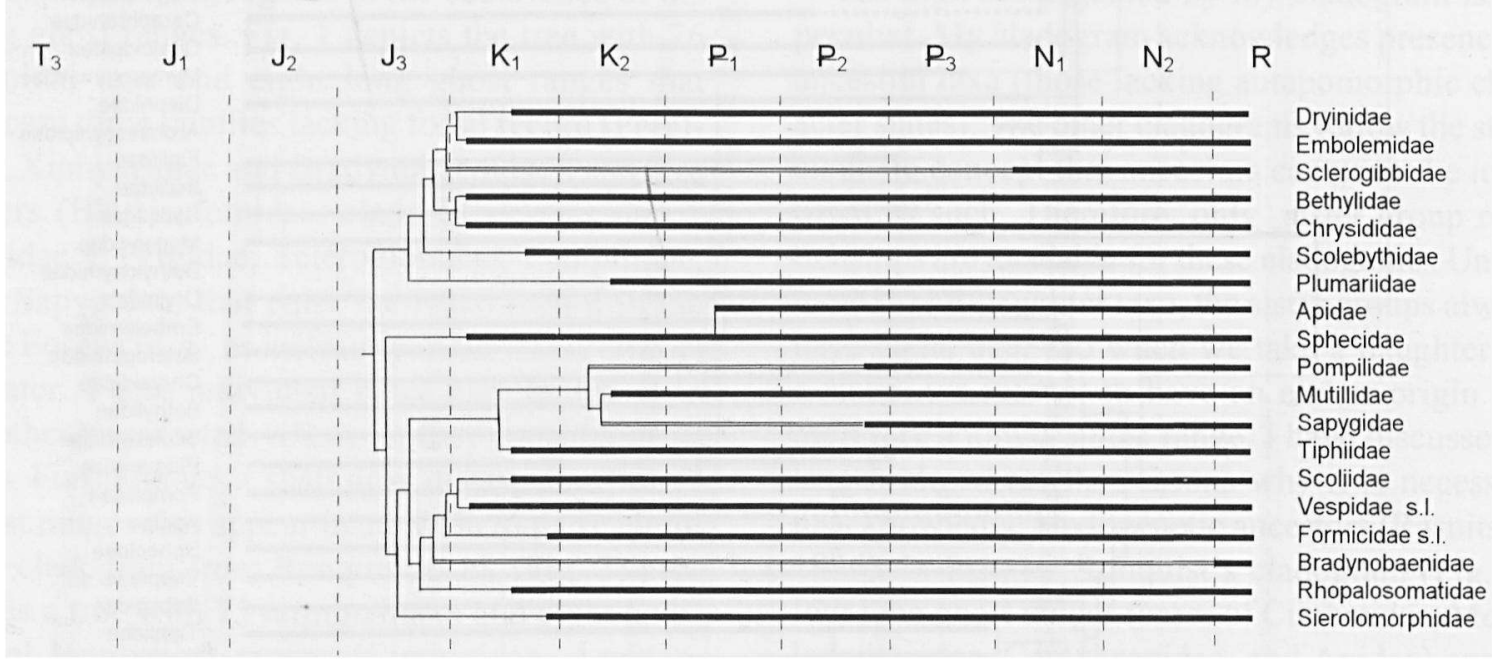

Fig. 5. Relation of the aculeate taxa as calculated by Brothers and Carpenter (1993: fig. 11), formatted after Figs. 1, 2. 


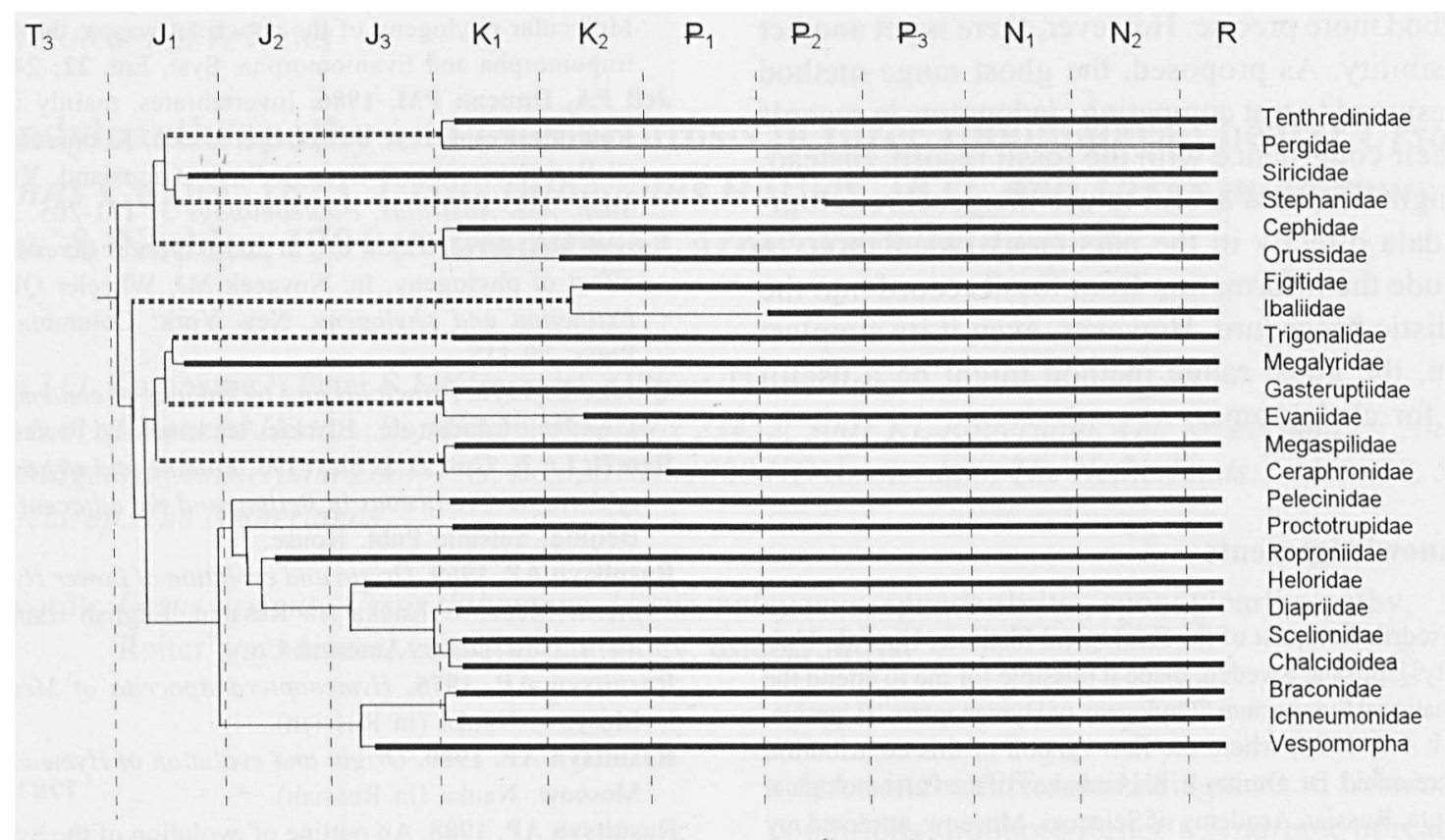

Fig. 6. Molecular phylogeny of hymenopteran taxa as calculated by Dowton and Austin (1994: fig. 3), for symphytan families, Orussidae and Stephanidae, and by Dowton et al. (1997: fig. 2) for the apocritans, formatted after Figs. 1, 2.

solely because they are considered to be sister and not daughter groups of Tenthredinidae, Praesiricidae, Megaspilidae, and Sphecidae, respectively. The same is true for three cases (Cimbicidae, Megalodontesidae and Cephidae) in Vilhelmsen's cladogram (Fig. 3); in my cladogram Cephidae is the daughter taxon of Sepulcidae. Of six long ghost ranges in Whitfield's tree (Fig. 4), five are absent in my cladogram because Trigonalidae and Ceraphronoidea (s.str.) are suggested there to descend directly from Megalyridae, Platygastroidea + Chalcidoidea and Cynipoidea - from the ancestral proctotrupoid family Mesoserphidae, and Ichneumonoidea + Aculeata from Ephialtitidae. In Dowton and Austin's cladogram (Fig. 6), there are seven additional long ghost ranges comparing to Fig. 1. Four of them result from the same causes: in my cladogram, Tenthredinoidea originate directly from Xyelidae, Cephidae from Sepulcidae, Trigonalidae from Megalyridae, and Evaniidae + Gasteruptiidae from Praeaulacidae.

The reasons why other long ghost ranges appear in Figs. 2, 3, 4 and 6 in addition to those seen in the Fig. 1, are not so evident. Possibly they are relevant to the phylogeny of Hymenoptera rather than to methodology of phylogenetics, and so they will be considered elsewhere.

\section{Conclusion}

The above observations indicate that the total amount of ghost ranges displayed by different phylogenetic trees for the same set of taxa does allow us to compare and evaluate the cladograms forming the background of these trees. Moreover, the results of application of the method are understandable and possible to explain, at least in part. That the cladogram from Rasnitsyn (1988) fits better to the fossil record than the majority of others, depends at least partially on the appreciation of mother and daughter groups in additional to the sister groups, these latter being the only legitimate ones in cladistics. At the same time, testing of the cladogram by Brothers and Carpenter (1993) indicates that the high score received by Rasnitsyn's (1988) cladogram from the present test is not a straightforward result of the method used there, i.e., the making of a cladogram by the method of Hennig ("paper and pencil" approach) instead of the automatic parsimony calculation, and an appreciation of the ancestor and descendant taxa.

Several ways to further development of the ghost range method may be proposed. The most evident one is the calculation of the length rather than the simple count of ghost ranges: this would make the 
method more precise. However, there is yet another possibility. As proposed, the ghost range method is designed to test competing cladograms in regards to their congruence with the fossil record. Instead, it might be found useful to use the geochronological data directly in the parsimony calculation, to include the information from fossil record into the cladistic procedure. However, even it its simplest form, the ghost range method might be a useful test for cladograms.

\section{Acknowledgements}

Dr. Fredrik Ronquist of the Zoological Institute, Uppsala University, Uppsala, Sweden, made it possible for me to attend the International Symposium "Phylogeny of Hymenoptera" (Uppsala, March 4-7, 1998) where the first version of this contribution was presented. Dr. Dmitry E. Shcherbakov of the Paleontological Institute, Russian Academy of Sciences, Moscow, attracted my attention to the publication by Brenton and Hitchin (1997), I am thankful to Igor Pavlinov of the Zoological Museum, Moscow State University, and to the anonymous reviewers whose advises were very useful for me. The work was supported in part by a grant F58AQ from The Leverhulme Trust to D. Quicke and $M$. Fitton.

\section{References}

Basíbuyuk HH, Rasnitsyn AP, Fitton MG, Quicke DLJ (2000). An archaic new genus of the Evaniidae (Insecta: Hymenoptera): implications for biology of ancestral evanioíds. Bull. Nat. Hist. Mus. (Geology) 56(1): 53-58.

Benton MJ, Hitchin R. 1997. Congruence between phylogenetic and stratigraphic data on the history of life. Proc. R. Soc. (Lond.) (B) 264: 885-890.

Brischke D. 1886. Die Hymenopteren des Bernsteins, Schr. Naturforsch. Ges. Danzig, N. F. 6: 278-279.

Brothers DJ, Carpenter JM. 1993. Phylogeny of Aculeata: Chrysidoidea and Vespoidea (Hymenoptera). J. Hym. Res. 2: 227-304.

Darling D Ch, Sharkey MJ. 1990. Order Hymenoptera. Bull. Amer. Mus, Nat. Hist. 195: 124-129.

Dlussky GM. 1999. The first find of the Formicoidea (Hymenoptera) in the Lower Cretaceous of the North Hemisphere. Paleontol. Zhurnal 3: 62-66 (in Russian, translated into English in Paleontol. J. 33: 274-277).

Dowton M, Austin AD. 1994. Molecular phylogeny of the insect order Hymenoptera: Apocritan relationships. Proc. Natl. Acad. Sci. USA 91: 991 1-9915.

Dowton M, Austin AD, Dillon N, Bartowsky E. 1997.
Molecular phylogeny of the apocritan wasps: the Proctotrupomorpha and Evaniomorpha. Syst. Ent. 22: 245-255.

Jell PA, Duncan PM. 1986. Invertebrates, mainly insects, from the freshwater, Lower Cretaceous, Koonwarra Fossil Bed (Korumburra Group), South Gippsland, Victoria. Mem. Ass. Australas. Palaeontologs 3: 111-205.

Norrel MA. 1992. Taxic origin and temporal diversity: the effect of phylogeny. In: Novacek MJ, Wheeler QD, eds. Extinction and phylogeny. New York: Columbìa Univ. Press: 89-118.

Quicke D. 1996. Principles and techniques of contemporary taxonomy. London etc.: Blackie Academic and Professional.

Ren D, Lu L, Guo Z, Ji Sh. 1995. Faunae and stratigraphy of Jurassic-Cretaceous in Beijing and the adjacent areas. Beijjing: Seismic Publ. House.

Rasnitsyn AP. 1969. Origin and evolution of Lower Hymenoptera. Moscow: Nauka (in Russian, English translation 1979, New Delhi: Amerind Co.).

Rasnitsyn AP. 1975. Hymenoptera Apocrita of Mesozoic. Moscow: Nauka (in Russian).

Rasnitsyn AP. 1980. Origin and evolution of Hymenoptera. Moscow: Nauka (in Russian).

Rasnitsyn AP. 1988. An outline of evolution of the hymenopterous insects (order Vespida). Oriental Insects 22: 115I45.

Rasnitsyn AP. 1990. Hymenoptera. In: Ponomarenko AG, ed. Late Mesozoic insects of Eastern Transbaikalian. Moscow: Nauka: 177-205 (in Russian).

Rasnitsyn AP. 1993. New taxa of Sepulcidae. In: Ponomarenko AG, ed. Late Mesozoic insects of Eastern Transbaikalian. Moscow: Nauka: 80-99 (in Russian).

Rasnitsyn A P. 1996a. Conceptual issues in phylogeny, taxonomy, and nomenclature. Contrib. Zool. 66: 3-41.

Rasnitsyn AP. 1996b. New Early Cretaceous Embolemidae (Vespida $=$ Hymenoptera . Chrysidoidea). Mem. Ent. Soc. Washington 17: 183-187.

Rasnitsyn AP. (in press). An extremely primitive, aculeate wasp in the Cretaceous amber from New Jersey (Vespida: ?Sierolomorphidae), Bull Amer. Mus, Nat. Hist.

Rasnitsyn AP, Jarzembowski EA, Ross AJ. 1998. Wasps (Insecta: Vespida $=$ Hymenoptera) from the Purbeck and Wealden (Lower Cretaceous) of Southern England and their biostratigraphícal and paleoenvironmental significance. Cretac, Res, 19: 329-391.

Ronquist F, Rasnitsyn AP, Roy A, Eriksson K, Lindgren M. 1999. A cladistic reanalysis of Rasnitsyn's data on the higher-level phylogeny of the Hymenoptera. Zool. Scripta 28: 13-50.

Vilhelmsen L. 1997. The phylogeny of lower Hymenoptera (Insecta), with a summary of the early evolutionary history of the order. J. Zool. Syst. Evol. Res. 35: 49-70.

Whitfield JB. 1992. Phylogeny of the non-aculeate Apocrita and the evolution of parasitism in Hymenoptera. $J . H y m$. Res. 1: 3-14.

Received: 16 November 1999 